\title{
Improved Between-Satellite Single-Difference Precise Point Positioning Model Using Triple GNSS Constellations: GPS, Galileo, and BeiDou
}

\author{
Akram Afifi, Ahmed El-Rabbany \\ Department of Civil Engineering, Ryerson University, Toronto, Canada \\ Email: akram.afifi@ryerson.ca, rabbany@ryerson.ca
}

Received 23 March 2016; accepted 9 May 2016; published 12 May 2016

Copyright (C) 2016 by authors and Scientific Research Publishing Inc.

This work is licensed under the Creative Commons Attribution International License (CC BY). http://creativecommons.org/licenses/by/4.0/

(c) (i) Open Access

\section{Abstract}

This paper introduces a new dual-frequency precise point positioning (PPP) model, which combines the observations of three different GNSS constellations, namely GPS, Galileo, and BeiDou. Our model is based on between-satellite single-difference (BSSD) linear combination, which cancels out some receiver-related biases, including receiver clock error and non-zero initial phase bias of the receiver oscillator. The reference satellite can be selected from any satellite system GPS, Galileo, and BeiDou when forming BSSD linear combinations. Natural Resources Canada's GPS Pace PPP software is modified to enable a combined GPS, Galileo, and BeiDou PPP solution and to handle the newly introduced biases. A total of four data sets at four IGS stations are processed to verify the developed PPP model. Precise satellite orbit and clock products from the IGS-MGEX network are used to correct both of the GPS and Galileo measurements. It is shown that using the BSSD linear combinations improves the precision of the estimated parameters by about $25 \%$ compared with the GPS-only PPP solution. Additionally, the solution convergence time is reduced to 10 minutes for both BSSD scenarios, which represent about $50 \%$ improvement in comparison with the GPS-only PPP solution.

\section{Keywords}

PPP, BSSD, GPS, Galileo, BeiDou

\section{Introduction}

Global navigation satellite systems (GNSS) precise point positioning (PPP) has proven to be capable of provid- 
ing positioning accuracy at the sub-decimeter and decimeter levels in static and kinematic modes, respectively. PPP accuracy and convergence time are controlled by the ability to mitigate all potential error sources in the system. Several comprehensive studies have been published on the accuracy and convergence time of undifferrent combined GPS/Galileo PPP model [1]-[8]. PPP relies essentially on the availability and use of precise satellite products, namely orbital and clock corrections. At present, The Multi-GNSS Experiment (MGEX) of the International GNSS Service (IGS) provides the precise satellite orbital and clock corrections for all the GNSS [9].

A drawback of a single GNSS system such as Global Positioning System (GPS) is the limited number of visible satellites in urban areas. With the addition of Galileo and BeiDou satellites, a PPP solution based on the combined GPS, Galileo, and BeiDou observations becomes more feasible. Combining the three satellite constellations offers more visible satellites to users, which in turn enhance the satellite geometry and are expected to improve the overall positioning solution [7]. However, Combining GPS, Galileo, and BeiDou come at the expense of introducing additional biases to the observation mathematical models. These include the GPS to Galileo time offset, GPS to BeiDou time offset and hardware delays of both Galileo and BeiDou. More recently, Afifi and El-Rabbany [6] show that combining the un-differenced GPS and Galileo observations in a PPP model improves the solution convergence time by about $25 \%$, in comparison with the GPS-only counterpart. In addition, they show that the inter-system bias is largely constant over a one-hour observation time span, which they are used in their analysis, with a magnitude ranging from 30 to 60 nanoseconds depending on the GNSS receiver type. Tegedor et al. [10] present an analysis about the accuracy and availability of the quad-constellation (GPS, Galileo, BeiDou, and Glonass) PPP daily solutions using the MGEX datasets. In this study, the quad-constellation PPP model is developed and its performance is assessed in terms of positioning accuracy and convergence time through static and kinematic tests.

This paper develops triple GNSS (GPS, Galileo, and BeiDou) PPP model, which rigorously accounts for the additional combination biases. These additional biases are lumped together into a new unknown parameter, which is referred to as the inter-system bias, in the PPP mathematical model. The GPS receiver differential hardware delays are lumped to the GPS receiver clock error in all the developed PPP models. The hydrostatic component of the tropospheric zenith path delay is modelled through the Hopfield model, while the wet component is considered as an additional unknown parameter [7] [11]. All remaining errors and biases are accounted for using existing models as shown in Kouba [12]. In the developed models, GPS L1/L2, Galileo E1/E5a, and BeiDou B1/B2 are used dual-frequency ionosphere-free linear combinations. Sequential least-squares estimation technique is used to get the best estimates for the inter-system bias parameter. The inter-system bias parameter is found to be essentially constant over the observation time span (one hour) and receiver-dependent. The precision of the estimated parameters improves by about $25 \%$ compared with the GPS-only PPP solution. Additionally, the solution convergence time is reduced to 10 minutes for both BSSD scenarios, which represent about $50 \%$ improvement in comparison with the GPS-only PPP solution.

\section{Un-Differenced PPP Models}

Traditionally, PPP has been carried out using dual-frequency ionosphere-free linear combinations of carrierphase and pseudorange GPS measurements. Equations (1) to (4) show the ionosphere free linear combination of GPS, Galileo, and BeiDou observations [13].

$$
\begin{aligned}
& P_{G_{I F}}=\rho_{G}+c\left[d t_{r G}-d t^{s}\right]+c\left[\alpha d_{P 1}-\beta d_{P 2}\right]_{r}+c\left[\alpha d_{P 1}-\beta d_{P 2}\right]^{s}+T_{G}+\varepsilon_{P G_{I F}} \\
& P_{E_{I F}}=\rho_{E}+c\left[d t_{r G}-G G T O-d t^{s}\right]+c\left[\alpha d_{E 1}-\beta d_{E 5 a}\right]_{r}+c\left[\alpha d_{E 1}-\beta d_{E 5 a 2}\right]^{s}+T_{E}+\varepsilon_{E_{I F}} \\
& P_{B_{I F}}=\rho_{B}+c\left[d t_{r G}-G B-d t^{s}\right]+c\left[\alpha d_{B 1}-\beta d_{B 2}\right]_{r}+c\left[\alpha d_{B 1}-\beta d_{B 2}\right]^{s}+T_{B}+\varepsilon_{B_{I F}} \\
& \Phi_{G_{I F}}=\rho_{G}+c\left[d t_{r G}-d t^{s}\right]+c\left[\alpha \delta_{L 1}-\beta \delta_{L 2}\right]_{r}+c\left[\alpha \delta_{L 1}-\beta \delta_{L 2}\right]^{s}+T_{G}+N_{G_{I F}}+\phi_{r 0_{G_{I F}}}+\phi_{0_{G_{I F}}}^{s}+\varepsilon_{\Phi G_{I F}} \\
& \Phi_{E_{I F}}=\rho_{E}+c\left[d t_{r G}-G G T O-d t^{s}\right]+c\left[\alpha \delta_{E 1}-\beta \delta_{E 5 a}\right]_{r}+c\left[\alpha \delta_{E 1}-\beta \delta_{E 5 a}\right]^{s}+T_{E}+N_{E_{I F}}+\phi_{r 0_{E I F}}+\phi_{0_{E I F}}^{s}+\varepsilon_{\Phi E_{I F}} \\
& \Phi_{B_{I F}}=\rho_{B}+c\left[d t_{r G}-G B-d t^{s}\right]+c\left[\alpha \delta_{B 1}-\beta \delta_{B 2}\right]_{r}+c\left[\alpha \delta_{B 1}-\beta \delta_{B 2}\right]^{s}+T_{B}+N_{B_{I F}}+\phi_{r_{B_{I F}}}+\phi_{0_{B_{I F}}}^{s}+\varepsilon_{\Phi_{I F}}
\end{aligned}
$$


where the subscripts $G, E$, and $B$ refer to the GPS, Galileo, and BeiDou satellite systems, respectively; $P_{G_{I F}}$, $P_{E_{I F}}$ and $P_{B_{I F}}$ are the ionosphere-free pseudoranges in meters for GPS, Galileo, and BeiDou systems, respectively; $\Phi_{G_{I F}}, \Phi_{E_{I F}}$ and $\Phi_{B_{I F}}$ are the ionosphere-free carrier phase measurements in meters for GPS, Galileo, and BeiDou systems, respectively; GGTO is the GPS to Galileo time offset; GB is the GPS to BeiDou time offset; $\rho$ is the true geometric range from receiver at reception time to satellite at transmission time in meter; $d t_{r}, d t^{s}$ are the clock errors in seconds for the receiver at signal reception time and the satellite at signal transmission time, respectively; $d_{P 1 r}, d_{P 2 r}, d_{E 1 r}, d_{E 5 a r}, d_{B 1 r}, d_{B 2 r}$ are frequency-dependent code hardware delays for the receiver at reception time in seconds; $d_{P 1}^{S}, d_{P 2}^{S}, d_{E 1}^{S}, d_{E 5 a}^{S}, d_{B 1}^{S}, d_{B 2 a}^{S}$ are frequency-dependent code hardware delays for the satellite at transmission time in seconds; $\delta_{L 1 r}, \delta_{L 2 r}, \delta_{E 1 r}, \delta_{E 5 a r}, \delta_{B 1 r}, \delta_{B 2 r}$ are frequency-dependent carrier-phase hardware delays for the receiver at reception time in seconds; $\delta_{L 1}^{S}, \delta_{L 2}^{S}$, $\delta_{E 1}^{S}, \quad \delta_{E 5 a}^{S}, \quad \delta_{B 1}^{S}, \quad \delta_{B 2}^{S}$ are frequency-dependent carrier-phase hardware delays for the satellite at transmission time in seconds; $T$ is the tropospheric delay in meter; $N_{G_{I F}}, N_{E_{I F}}, N_{B_{I F}}$ are the ionosphere-free linear combinations of the ambiguity parameters for both GPS, Galileo, and BeiDou carrier-phase measurements in meters, respectively; $\phi_{r 0_{G F}}, \phi_{0_{G_{I F}}}^{s}, \phi_{r 0_{E_{I F}}}, \phi_{0_{E_{I F}}}^{s}, \phi_{r 0_{B_{I F}}}, \phi_{0_{B_{I F}}}^{s}$ are ionosphere-free linear combinations of frequencydependent initial fractional phase biases in the receiver and satellite channels for both GPS, Galileo, and BeiDou in meters, respectively; $c$ is the speed of light in vacuum in meter per second; $\varepsilon_{P_{I F}}, \varepsilon_{E_{I F}}, \varepsilon_{\Phi G_{I F}}, \varepsilon_{\Phi E_{I F}}, \varepsilon_{B_{I F}}$, $\varepsilon_{\Phi_{B_{I F}}}$ are the ionosphere-free linear combinations of the relevant noise and un-modeled errors in meter; $\alpha_{G}$, $\beta_{G}, \alpha_{E}, \beta_{E}, \alpha_{B}, \beta_{B}$ are the ionosphere-free linear combination coefficients for GPS, Galileo, and BeiDou which are given, respectively, by: $\alpha_{G}=\frac{f_{1}^{2}}{f_{1}^{2}-f_{2}^{2}}, \quad \beta_{G}=\frac{f_{2}^{2}}{f_{1}^{2}-f_{2}^{2}}, \quad \alpha_{E}=\frac{f_{E 1}^{2}}{f_{E 1}^{2}-f_{E 5 a}^{2}}, \quad \beta_{E}=\frac{f_{E 5 a}^{2}}{f_{E 1}^{2}-f_{E 5 a}^{2}}$, $\alpha_{B}=\frac{f_{B 1}^{2}}{f_{B 1}^{2}-f_{B 2}^{2}}, \quad \beta_{B}=\frac{f_{B 2}^{2}}{f_{B 1}^{2}-f_{B 2}^{2}}$.

Where $f_{1}$ and $f_{2}$ are GPS $L_{1}$ and $L_{2}$ signals frequencies; $f_{E 1}$ and $f_{E 5 a}$ are Galileo $E_{1}$ and $E_{5 a}$ signals frequencies; $f_{B 1}$ and $f_{B 2}$ are BeiDou $B_{1}$ and $B_{2}$ signals frequencies.

$$
\begin{gathered}
N_{G_{I F}}=\alpha_{G} \lambda_{1} N_{1}-\beta_{G} \lambda_{2} N_{2} \\
N_{E_{I F}}=\alpha_{E} \lambda_{E 1} N_{E 1}-\beta_{E} \lambda_{E 5 a} N_{E 5 a} \\
N_{B_{I F}}=\alpha_{B} \lambda_{B 1} N_{B 1}-\beta_{B} \lambda_{B 2} N_{B 2}
\end{gathered}
$$

where $\lambda_{1}$ and $\lambda_{2}$ are the GPS $L_{1}$ and $L_{2}$ signals wavelengths in meters; $\lambda_{E 1}$ and $\lambda_{E 5 a}$ are the Galileo $E_{1}$ and $E_{5 a}$ signals wavelengths in meters; $\lambda_{B 1}$ and $\lambda_{B 2}$ are the BeiDou $B_{1}$ and $B_{2}$ signals wavelengths in meters; $N_{1}, N_{2}$ are the integer ambiguity parameters of GPS signals $L_{1}$ and $L_{2}$, respectively; $N_{E 1}, N_{E 5 a}$ are the integer ambiguity parameters of Galileo signals $E_{1}$ and $E_{5 a}$, respectively; $N_{B 1}, N_{B 2}$ are the integer ambiguity parameters of BeiDou signals $B_{1}$ and $B_{2}$, respectively.

Precise orbit and satellite clock corrections of IGS-MGEX networks are produced for both GPS/Galileo observations and are referred to GPS time. IGS precise GPS satellite clock correction includes the effect of the ionosphere-free linear combination of the satellite hardware delays of $L_{1} / L_{2} P(Y)$ code, while the Galileo counterpart includes the effect of the ionosphere-free linear combination of the satellite hardware delays of the Galileo $E_{1} / E_{5 a}$ pilot code. In addition, BeiDou satellite clock correction includes the effect of the ionosphere-free linear combination of the satellite hardware delays of $B_{1} / B_{2}$ code [9]. By applying the precise clock products for both GPS/Galileo observations, Equations (1)-(4) will take the following form:

$$
\begin{gathered}
P_{G_{I F}}=\rho_{G}+c\left[d t_{r G}-d t_{\text {prec }}^{s}\right]+c\left[\alpha d_{P 1}-\beta d_{P 2}\right]_{r}+T_{G}+\varepsilon_{P G_{I F}} \\
P_{E_{I F}}=\rho_{E}+c\left[d t_{r G}-d t_{\text {prec }}^{s}\right]+c\left[\alpha d_{E 1}-\beta d_{E 5 a}\right]_{r}+T_{E}+\varepsilon_{E_{I F}} \\
P_{B_{I F}}=\rho_{B}+c\left[d t_{r G}-d t_{\text {prec }}^{s}\right]+c\left[\alpha d_{B 1}-\beta d_{B 2}\right]_{r}+T_{B}+\varepsilon_{B_{I F}} \\
\Phi_{G_{I F}}=\rho_{G}+c d t_{r G}-c\left[d t_{p r e c}^{s}+\left[\alpha d_{P 1}-\beta d_{P 2}\right]^{s}\right]+c\left[\alpha \delta_{L 1}-\beta \delta_{L 2}\right]_{r}-c\left[\alpha \delta_{L 1}-\beta \delta_{L 2}\right]^{s} \\
+T_{G}+N_{G_{I F}}+\phi_{r 0_{G F}}+\phi_{0_{G I}}^{s}+\varepsilon_{\Phi G_{I F}}
\end{gathered}
$$




$$
\begin{aligned}
\Phi_{E_{I F}}= & \rho_{E}+c d t_{r G}-c\left[d t_{p r e c}^{s}+\left[\alpha d_{E 1}-\beta d_{E 5 a}\right]^{s}\right]+c\left[\alpha \delta_{E 1}-\beta \delta_{E 5 a}\right]_{r}-c\left[\alpha \delta_{E 1}-\beta \delta_{E 5 a}\right]^{s} \\
& +T_{E}+N_{E_{I F}}+\phi_{r 0_{E_{I F}}}+\phi_{0_{E_{I F}}}^{s}+\varepsilon_{\Phi E_{I F}} \\
\Phi_{B_{I F}}= & \rho_{B}+c d t_{r G}-c\left[d t_{p r e c}^{s}+\left[\alpha d_{B 1}-\beta d_{B 2}\right]^{s}\right]+c\left[\alpha \delta_{B 1}-\beta \delta_{B 2}\right]_{r}-c\left[\alpha \delta_{B 1}-\beta \delta_{B 2}\right]^{s} \\
& +T_{B}+N_{B_{I F}}+\phi_{r 0_{B_{I F}}}+\phi_{0_{B_{I F}}}^{s}+\varepsilon_{\Phi B_{I F}}
\end{aligned}
$$

For simplicity, the receiver and satellite hardware delays will take the following forms:

$$
\begin{array}{ll}
b_{r_{P}}=c\left[\alpha d_{P 1}-\beta d_{P 2}\right]_{r} & b_{P}^{s}=c\left[\alpha d_{P 1}-\beta d_{P 2}\right]^{s} \\
b_{r_{E}}=c\left[\alpha d_{E 1}-\beta d_{E 5 a}\right]_{r} & b_{E}^{s}=c\left[\alpha d_{E 1}-\beta d_{E 5 a}\right]^{s} \\
b_{r_{B}}=c\left[\alpha d_{B 1}-\beta d_{B 2}\right]_{r} & b_{B}^{s}=c\left[\alpha d_{B 1}-\beta d_{B 2}\right]^{s} \\
b_{r_{\Phi}}=c\left[\alpha \delta_{L 1}-\beta \delta_{L 2}\right]_{r}+\phi_{r 0_{G_{I F}}} & b_{\Phi}^{s}=c\left[\alpha \delta_{L 1}-\beta \delta_{L 2}\right]^{s}+\phi_{0_{G_{I F}}^{s}}^{s} \\
b_{r_{E \Phi}}=c\left[\alpha \delta_{E 1}-\beta \delta_{E 5 a}\right]_{r}+\phi_{r 0_{E_{I F}}} & b_{E \Phi}^{s}=c\left[\alpha \delta_{E 1}-\beta \delta_{E 5 a}\right]^{s}+\phi_{0_{E_{I F}}}^{s} \\
b_{r_{B \Phi}}=c\left[\alpha \delta_{B 1}-\beta \delta_{B 2}\right]_{r}+\phi_{r 0_{B_{I F}}} & b_{B \Phi}^{s}=c\left[\alpha \delta_{B 1}-\beta \delta_{B 2}\right]^{s}+\phi_{0_{B_{I F}}}^{s}
\end{array}
$$

In the combined GPS, Galileo and BeiDou un-differenced PPP model, the GPS receiver clock error is lumped with the GPS receiver differential code biases. In order to maintain consistency in the estimation of a common receiver clock offset, this convention is used when combining the ionosphere-free linear combination of GPS $L_{1} / L_{2}$, Galileo $E_{1} / E_{5 a}$ and BeiDou $B_{1} / B_{2}$ observations in a PPP model. This, however, introduces an additional bias in the Galileo ionosphere-free PPP mathematical model, which represents the difference in the receiver differential code biases of both systems. Such an additional bias is commonly known as the inter-system bias, which is referred to as ISB in this paper. In our PPP mode, the Hopfield tropospheric correction model along with the Vienna mapping function are used to account for the hydrostatic component of the tropospheric delay [11] [14]. Other corrections are also applied, including the effect of ocean loading [15] [16], Earth tide [12], carrier-phase windup [8] [17], Sagnac [18], relativity [7], and satellite and receiver antenna phase-center variations [19]. The noise terms are modeled stochastically using an exponential model, as described in Afifi and El-Rabbany [6]. With the above consideration, the GPS/Galileo ionosphere-free linear combinations of both pseudorange and carrier phase can be written as:

$$
\begin{gathered}
P_{G_{I F}}=\rho_{G}+\tilde{d} t_{r G}-d t_{\text {prec }}^{s}+T_{G}+\varepsilon_{P G_{I F}} \\
P_{E_{I F}}=\rho_{E}+\tilde{d} t_{r G}-d t_{\text {prec }}^{s}+I S B_{G E}+T_{E}+\varepsilon_{E_{I F}} \\
P_{B_{I F}}=\rho_{B}+\tilde{d} t_{r G}-d t_{\text {prec }}^{s}+I S B_{G B}+T_{B}+\varepsilon_{B_{I F}} \\
\Phi_{G_{I F}}=\rho_{G}+\tilde{d} t_{r G}-d t_{\text {prec }}^{s}+T_{G}+\tilde{N}_{G_{I F}}+\varepsilon_{\Phi G_{I F}} \\
\Phi_{E_{I F}}=\rho_{E}+\tilde{d} t_{r G}-d t_{\text {prec }}^{s}+T_{E}+\tilde{N}_{E_{I F}}+I S B_{G E}+\varepsilon_{\Phi E_{I F}} \\
\Phi_{B_{I F}}=\rho_{B}+\tilde{d} t_{r G}-d t_{\text {prec }}^{s}+T_{B}+\tilde{N}_{B_{I F}}+I S B_{G B}+\varepsilon_{\Phi B_{I F}}
\end{gathered}
$$

where $\tilde{d}_{r G}$ represents the sum of the receiver clock error and receiver hardware delay $\tilde{d} t_{r G}=c d t_{r G}+b_{r_{p}}$; ISB is the inter system bias as follows $I S B_{G E}=b_{r_{E}}-b_{r_{p}} ; I S B_{G B}=b_{r_{B}}-b_{r_{p}} ; \tilde{N}_{G_{I F}}, \tilde{N}_{B_{I F}}$ and are given by:

$$
\begin{gathered}
\tilde{N}_{G_{I F}}=N_{G_{I F}}+b_{r_{\Phi}}+b_{r_{P}}-b_{\Phi}^{s}-b_{P}^{s} \\
\tilde{N}_{E_{I F}}=N_{E_{I F}}+b_{r_{E \Phi}}+b_{r_{P}}-b_{E \Phi}^{s}-b_{E}^{s} \\
\tilde{N}_{B_{I F}}=N_{B_{I F}}+b_{r_{B \Phi}}+b_{r_{P}}-b_{B \Phi}^{s}-b_{B}^{s}
\end{gathered}
$$


When using the combined GPS, Galileo, and BeiDou un-differenced PPP model, the ambiguity parameters lose its integer nature as they are contaminated by receiver and satellite hardware delays. It should be pointed out that the number of unknown parameters in the combined PPP model equals the number of visible satellites from any system plus seven parameters, while the number of equations equals double the number of the visible satellites. This means that the redundancy equals $n_{G}+n_{E}+n_{B}-7$. In other words, at least 7 mixed satellites are needed for the solution to exist. In comparison with the GPS-only un-differenced scenario, which requires a minimum of 5 satellites for the solution to exist, the addition of Galileo or BeiDou satellites increases the redundancy by $n_{E}+n_{B}-2$. In other words, we need a minimum of three satellites from both Galileo and BeiDou systems in order to contribute to the solution.

As indicated earlier, In case of considering a GPS satellite is selected as a reference for all the GNSS observables [20]. Taking a GPS satellite as a reference and using Equations (16) to (21), we obtain:

$$
\begin{gathered}
\rho_{G, G}^{i j}+m_{f_{G, G}}^{i j} z p d_{w}+\tilde{\varepsilon}_{P G_{I F}}^{i j}-\tilde{P}_{G_{I F}}^{i j}=0 \\
\rho_{E, G}^{i k}+m_{f_{E, G}}^{i k} z p d_{w}+I S B_{G E}+\tilde{\varepsilon}_{P E_{I F}}^{i k}-\tilde{P}_{E G_{I F}}^{i k}=0 \\
\rho_{B, G}^{i h}+m_{f_{B, G}}^{i h} z p d_{w}+I S B_{G B}+\tilde{\varepsilon}_{P B_{I F}}^{i h}-\tilde{P}_{B G_{I F}}^{i B}=0 \\
\rho_{G, G}^{i j}+m_{f_{G, G}}^{i j} z p d_{w}+\tilde{N}_{G_{I F}}^{i j}+\tilde{\varepsilon}_{\Phi G_{I F}}^{i j}-\tilde{\Phi}_{G_{I F}}^{i j}=0 \\
\rho_{G, G}^{i j}+m_{f_{G, G}}^{i j} z p d_{w}+\tilde{N}_{G_{I F}}^{i j}+\tilde{\varepsilon}_{\Phi G_{I F}}^{i j}-\tilde{\Phi}_{G_{I F}}^{i j}=0 \\
\rho_{B, G}^{i h}+m_{f_{B, G}}^{i h} z p d_{w}+I S B_{G B}+\tilde{N}_{B G_{I F}}^{i h}+\tilde{\varepsilon}_{\Phi B_{I F}}^{i h}-\tilde{\Phi}_{B G_{I F}}^{i h}=0
\end{gathered}
$$

where $\tilde{N}_{G_{I F}}^{i j}, \tilde{N}_{E G_{I F}}^{i k}$ and $\tilde{N}_{B G_{I F}}^{i h}$ are given by:

$$
\begin{gathered}
\tilde{N}_{G_{I F}}^{i j}=N_{G_{I F}}^{i}-N_{G_{I F}}^{j}+b_{G \Phi}^{i j}-b_{P}^{i j} \\
\tilde{N}_{E G_{I F}}^{i k}=N_{G_{I F}}^{i}-N_{E_{I F}}^{k}+b_{r_{E \Phi}}-b_{r_{\Phi}}+b_{E \Phi}^{k}-b_{\Phi}^{i}+b_{P}^{i}-b_{E}^{k} \\
\tilde{N}_{B G_{I F}}^{i h}=N_{G_{I F}}^{i}-N_{B_{I F}}^{h}+b_{r_{B \Phi}}-b_{r_{\Phi}}+b_{B \Phi}^{h}-b_{\Phi}^{i}+b_{P}^{i}-b_{B}^{h}
\end{gathered}
$$

Similarly, when a Galileo satellite is selected as a reference, using Equations (16) to (21) leads to:

$$
\begin{aligned}
& \rho_{G, E}^{l j}+m_{f_{G, E}^{l j}}^{l j} z d_{w}-I S B_{G E}+\tilde{\varepsilon}_{P G_{I F}}^{l j}-\tilde{P}_{G E_{I F}}^{l j}=0 \\
& \rho_{E, E}^{l k}+m_{f_{E, E}}^{l k} z p d_{w}+\tilde{\varepsilon}_{P E_{I F}}^{l k}-\tilde{P}_{E_{I F}}^{l k}=0 \\
& \rho_{B, E}^{l h}+m_{f_{B, E}}^{l h} z p d_{w}+I S B_{G B}-I S B_{G E}+\tilde{\varepsilon}_{P B_{I F}}^{l h}-\tilde{P}_{B E_{I F}}^{l h}=0 \\
& \rho_{G, E}^{l j}+m_{f_{G, E}}^{l j} z p d_{w}-I S B_{G E}+\tilde{N}_{G E_{I F}}^{l j}+\tilde{\varepsilon}_{\Phi G_{I F}}^{l j}-\tilde{\Phi}_{G E_{I F}}^{l j}=0 \\
& \rho_{E, E}^{l k}+m_{f_{E, E}}^{l k} z p d_{w}+\tilde{N}_{E_{I F}}^{l k}+\tilde{\varepsilon}_{\Phi E_{I F}}^{l k}-\tilde{\Phi}_{E_{I F}}^{l k}=0 \\
& \rho_{B, E}^{l h}+m_{f_{B, E}}^{l h} z p d_{w}+I S B_{G B}-I S B_{G E}+\tilde{N}_{B E_{I F}}^{l h}+\tilde{\varepsilon}_{\Phi B_{I F}}^{l h}-\tilde{\Phi}_{B E_{I F}}^{l h}=0
\end{aligned}
$$

where, $\tilde{N}_{G E_{I F}}^{l}$ and $\tilde{N}_{E_{I F}}^{l k}$ and $\tilde{N}_{B E_{I F}}^{l h}$ are the BSSD non-integer ambiguity parameters lumped to the receiver and satellite hardware delays, which are given by:

$$
\begin{gathered}
\tilde{N}_{G E_{I F}}^{l j}=N_{E_{I F}}^{l}-N_{G_{I F}}^{j}+b_{r_{G \Phi}}-b_{r_{E \Phi}}+b_{G \Phi}^{j}-b_{E \Phi}^{l}+b_{E}^{l}-b_{P}^{j} \\
\tilde{N}_{E_{I F}^{l k}}^{l k}=N_{E_{I F}}^{l}-N_{E_{I F}}^{k}+b_{E \Phi}^{l k}-b_{E}^{l k} \\
\tilde{N}_{B E_{I F}^{l l}}^{l h}=N_{E_{I F}}^{l}-N_{B_{I F}}^{h}+b_{r_{B \Phi}}-b_{r_{E \Phi}}+b_{B \Phi}^{h}-b_{E \Phi}^{l}+b_{E}^{l}-b_{B}^{h}
\end{gathered}
$$

In case of selecting a BeiDou satellite as a reference, Equations (16) to (21) leads to:

$$
\rho_{G, B}^{h j}+m_{f_{G, B}}^{h j} z p d_{w}-I S B_{G B}+\tilde{\varepsilon}_{P G_{I F}}^{h j}-\tilde{P}_{G B_{I F}}^{h j}=0
$$




$$
\begin{gathered}
\rho_{E, B}^{h k}+m_{f_{E, B}}^{h k} z p d_{w}+I S B_{G E}-I S B_{G B}+\tilde{\varepsilon}_{P E_{I F}}^{h k}-\tilde{P}_{E B_{I F}}^{h k}=0 \\
\rho_{B, B}^{h u}+m_{f_{B, B}}^{h u} z p d_{w}+\tilde{\varepsilon}_{P B_{I F}}^{h u}-\tilde{P}_{B_{I F}}^{h u}=0 \\
\rho_{G, B}^{h j}+m_{f_{G, B}}^{h j} z p d_{w}-I S B_{G B}+\tilde{N}_{G B_{I F}}^{h j}+\tilde{\varepsilon}_{\Phi G_{I F}}^{h j}-\tilde{\Phi}_{G B_{I F}}^{h j}=0 \\
\rho_{E, B}^{h k}+m_{f_{E, B}^{h k}}^{h k} z p d_{w}+I S B_{G E}-I S B_{G B}+\tilde{N}_{B E_{I F}}^{h k}+\tilde{\varepsilon}_{\Phi E_{I F}}^{h k}-\tilde{\Phi}_{E B_{I F}}^{h k}=0 \\
\rho_{B, B}^{h u}+m_{f_{B, B}}^{h u} z p d_{w}+\tilde{N}_{B_{I F}}^{h u}+\tilde{\varepsilon}_{\Phi B_{I F}}^{h u}-\tilde{\Phi}_{B_{I F}}^{h u}=0
\end{gathered}
$$

where, $\tilde{N}_{G B_{I_{F}}}^{h j}, \tilde{N}_{E B_{I F}}^{h k}$ and $\tilde{N}_{B_{I F}}^{h u}$ are the BSSD non-integer ambiguity parameters lumped to the receiver and satellite hardware delays, which are given by:

$$
\begin{gathered}
\tilde{N}_{G B_{I F}}^{h j}=N_{B_{I F}}^{h}-N_{G_{I F}}^{j}+b_{r_{G \Phi}}-b_{r_{B \Phi}}+b_{G \Phi}^{j}-b_{B \Phi}^{h}+b_{B}^{h}-b_{P}^{j} \\
\tilde{N}_{E B_{I F}}^{h k}=N_{B_{I F}}^{h}-N_{E_{I F}}^{k}+b_{r_{E \Phi}}-b_{r_{B \Phi}}+b_{E \Phi}^{k}-b_{B \Phi}^{h}+b_{B}^{h}-b_{E}^{k} \\
\tilde{N}_{B_{I F}}^{h u}=N_{B_{I F}}^{h}-N_{B_{I F}}^{u}+b_{B \Phi}^{h u}-b_{B}^{h u}
\end{gathered}
$$

\section{Least Squares Estimation Technique}

Under the assumption that the observations are uncorrelated and the errors are normally distributed with zero mean, the covariance matrix of the un-differenced observations takes the form of a diagonal matrix. The elements along the diagonal line represent the variances of the code and carrier phase measurements. In our solution, we consider that the ratio between the standard deviation of the code and carrier-phase measurements to be 100. When forming BSSD, however, the differenced observations become mathematically correlated. This leads to a fully populated covariance matrix at a particular epoch.

The general linearized form for the above observation equations around the initial (approximate) vector $\boldsymbol{u}^{0}$ and observables $\boldsymbol{I}$ can be written in a compact form as:

$$
\boldsymbol{f}(\boldsymbol{u}, \boldsymbol{l}) \approx A \Delta \boldsymbol{u}-\boldsymbol{w}-\boldsymbol{r} \approx 0
$$

where $\boldsymbol{u}$ is the vector of unknown parameters; $\boldsymbol{A}$ is the design matrix, which includes the partial derivatives of the observation equations with respect to the unknown parameters $\boldsymbol{u} ; \boldsymbol{\Delta u}$ is the unknown vector of corrections to the approximate parameters $\boldsymbol{u}^{0}$, i.e., $\boldsymbol{u}=\boldsymbol{u}^{0}+\boldsymbol{\Delta} \boldsymbol{u} ; \boldsymbol{w}$ is the misclosure vector and $\boldsymbol{r}$ is the vector of residuals. The sequential least-squares solution for the unknown parameters $\Delta \boldsymbol{u}_{\boldsymbol{i}}$ at an epoch $i$ can be obtained from (Vanicek and Krakiwsky, 1986):

$$
\begin{gathered}
\Delta \boldsymbol{u}_{i}=\Delta \boldsymbol{u}_{i-1}+\boldsymbol{M}_{i-1}^{-1} \boldsymbol{A}_{i}^{\mathrm{T}}\left(\boldsymbol{C}_{l_{i}}+\boldsymbol{A}_{i} \boldsymbol{M}_{i-1}^{-1} \boldsymbol{A}_{i}^{\mathrm{T}}\right)^{-1}\left[\boldsymbol{w}_{i}-\boldsymbol{A}_{i} \Delta \boldsymbol{u}_{i-1}\right] \\
\boldsymbol{M}_{i}^{-1}=\boldsymbol{M}_{i-1}^{-1}-\boldsymbol{M}_{i-1}^{-1} \boldsymbol{A}_{i}^{\mathrm{T}}\left(\boldsymbol{C}_{l_{i}}+\boldsymbol{A}_{i} \boldsymbol{M}_{i-1}^{-1} \boldsymbol{A}^{\mathrm{T}}\right)^{-1} \boldsymbol{A}_{i} \boldsymbol{M}_{i-1}^{-1} \\
\boldsymbol{C}_{\Delta u_{i}}=\boldsymbol{M}_{i}^{-1}=\boldsymbol{M}_{i-1}^{-1}-\boldsymbol{M}_{i-1}^{-1} \boldsymbol{A}_{i}^{\mathrm{T}}\left(\boldsymbol{C}_{l_{i}}+\boldsymbol{A}_{i} \boldsymbol{M}_{i-1}^{-1} \boldsymbol{A}^{\mathrm{T}}\right)^{-1} \boldsymbol{A}_{i} \boldsymbol{M}_{i-1}^{-1}
\end{gathered}
$$

where $\Delta \boldsymbol{u}_{i-1}$ is the least-squares solution for the estimated parameters at epoch $i-1 ; \boldsymbol{M}$ is the matrix of the normal equations; $\boldsymbol{C}_{l}$ and $\boldsymbol{C}_{\Delta u}$ are the covariance matrices of the observations and unknown parameters, respectively. It should be pointed out that the usual batch least-squares adjustment should be used in the first epoch, i.e., for $i=1$. The batch solution for the estimated parameters and the inverse of the normal equation matrix are given, respectively, by Vanicek and Krakiwsky [21]:

$$
\begin{gathered}
\Delta \boldsymbol{u}_{1}=\left[\boldsymbol{C}_{x^{0}}^{-1}+\boldsymbol{A}_{1}^{\mathrm{T}} \boldsymbol{C}_{l_{1}}^{-1} \boldsymbol{A}_{1}\right]^{-1} \boldsymbol{A}_{1}^{\mathrm{T}} \boldsymbol{C}_{l_{1}}^{-1} \boldsymbol{w}_{1} \\
\boldsymbol{M}_{1}^{-1}=\left[\boldsymbol{C}_{x^{0}}^{-1}+\boldsymbol{A}_{1}^{\mathrm{T}} \boldsymbol{C}_{l_{1}}^{-1} \boldsymbol{A}_{1}\right]^{-1}
\end{gathered}
$$

where $\boldsymbol{C}_{x^{0}}$ is a priori covariance matrix for the approximate values of the unknown parameters. 


\section{Results and Discussion}

To verify the developed combined PPP models, GPS, Galileo, and BeiDou observations at four globally distributed stations (Figure 1) were selected from the IGS tracking network [19]. Those stations are occupied by GNSS receivers, which are capable of simultaneously tracking the GNSS constellations. Only one hour of observations with maximum possible number of Galileo and BeiDou satellites of each data set is considered in our analysis. All data sets have an interval of 30 seconds.

The positioning results for stations DLF1 are presented below. Similar results are obtained for the other stations. However, a summary of the convergence times and the three-dimensional PPP solution standard deviations are presented below for all stations. Natural Resources Canada's GPSPace PPP software was modified to handle data from GPS, Galileo, and BeiDou systems, which enables a combined PPP solution as detailed above. In addition to the combined PPP model, we also obtained the solutions of the un-differenced ionosphere-free GPS-only which is used to assess the performance of the newly developed PPP model. Figure 2 summarizes the satellite availability during the analysis time (one hour) for each system at DLF1 station.

As shown in Figure 2, the GPS system offers eight visible satellites for one hour, however by adding the Galileo system the number of visible satellites will be 13 satellite. In case of combining GPS and BeiDou the number

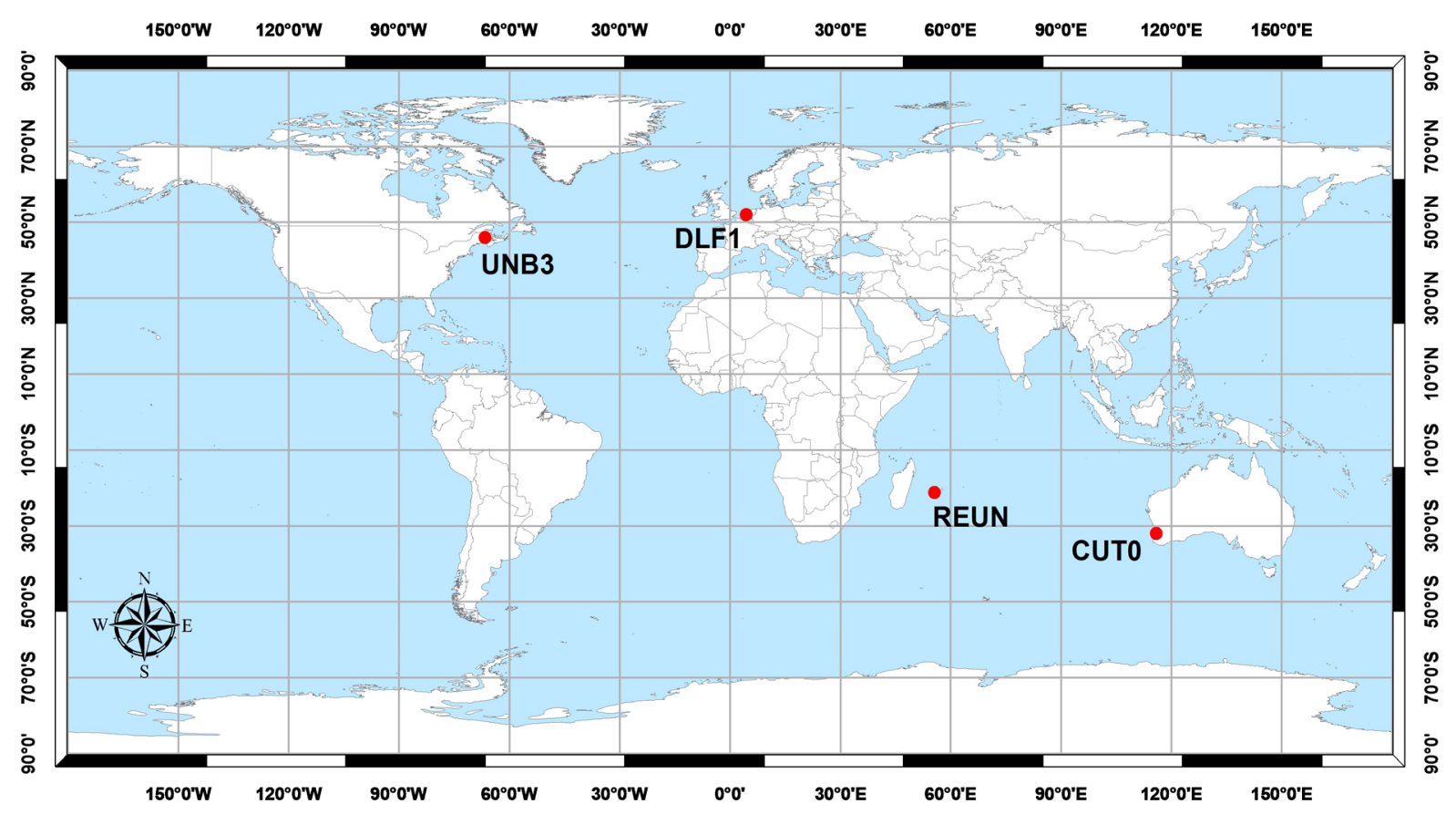

Figure 1. Analysis stations.

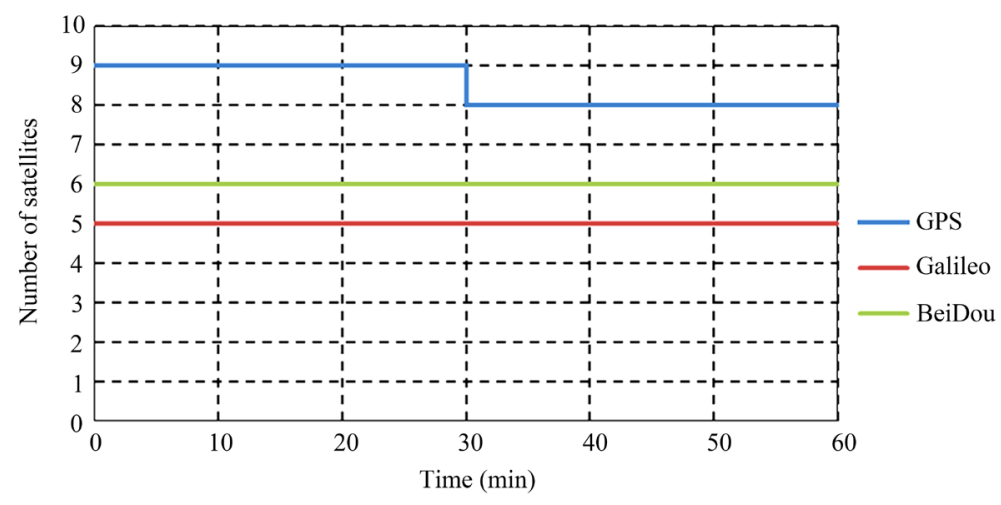

Figure 2. DLF1 station GNSS satellite availability. 
of visible satellites will be 14 satellites, however by combining the three satellite systems the number of visible satellites will be 19 satellites. Figure 3 shows the positioning results in the East, North, and Up directions, respectively, for the GPS-only PPP model. As can be seen, the un-differenced GPS-only PPP solution indicates that the model is capable of obtaining a sub-decimetre level accuracy. However the solution takes about 20 minutes to converge to decimetre level accuracy.

Figure 4 shows the combined GPS/Galileo/BeiDou PPP model positioning results. As shown in Figure 4. The convergence time of the combined GPS/Galileo/BeiDou PPP model has a convergence time of 15 minutes to reach the decimetre level of accuracy.

As mentioned earlier, the reference satellite can be considered from any constellations of the GNSS. In this paper the BSSD PPP model is formed using different reference satellite from each constellation: the first considers a GPS satellite as a reference for all GNSS observables, while the second considers a Galileo satellite as a reference and the third considered a BeiDou satellite as a reference satellite. As can be seen in Figure 5, almost identical positioning results are obtained with an average convergence time equals 10 minutes. In comparison with the GPS-only PPP model, the newly developed BSSD model improved the PPP solution convergence by about $50 \%$.

Figure 6 summarizes the convergence times for all combined PPP models, which confirm the PPP solution consistency at all stations.

To further assess the performance of the various PPP models, the solution output is sampled every 10 minutes and the standard deviation of the computed station coordinates is calculated for each sample. Figure 7 shows the position standard deviations in the East, North, and Up directions, respectively. Examining the standard deviations of the combined PPP models is improved comparing to the GPS-only PPP model. As the number of epochs, and consequently the number of measurements, increases the performance of the various models tends to be comparable.

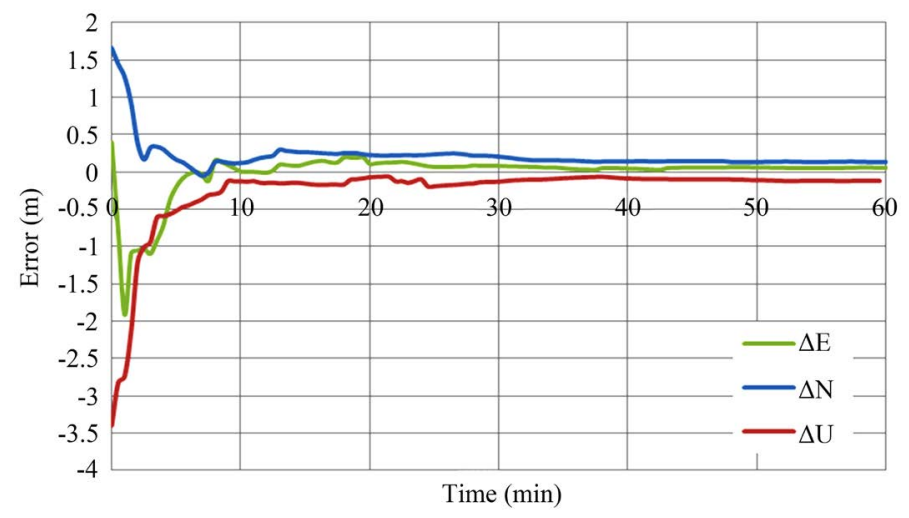

Figure 3. The positioning results of the GPS-only PPP model.

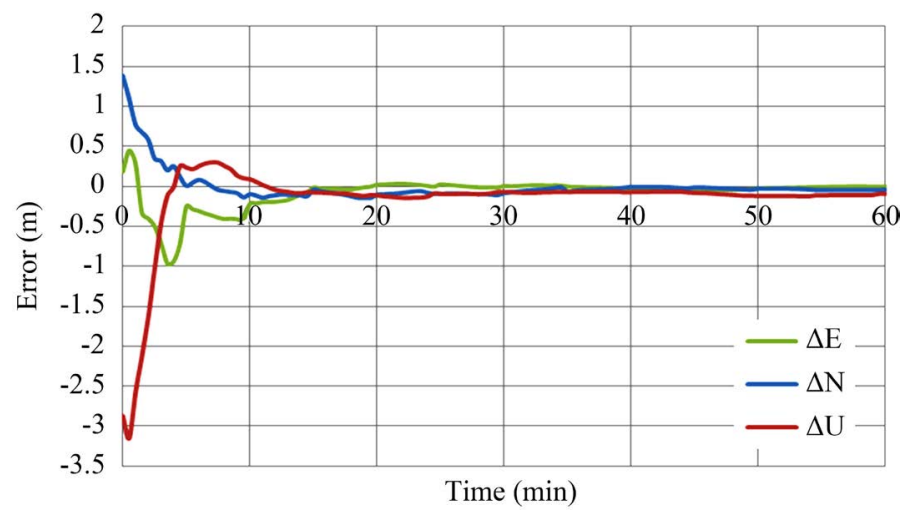

Figure 4. The positioning results of the un-differenced GPS/Galileo/ BeiDou PPP model. 


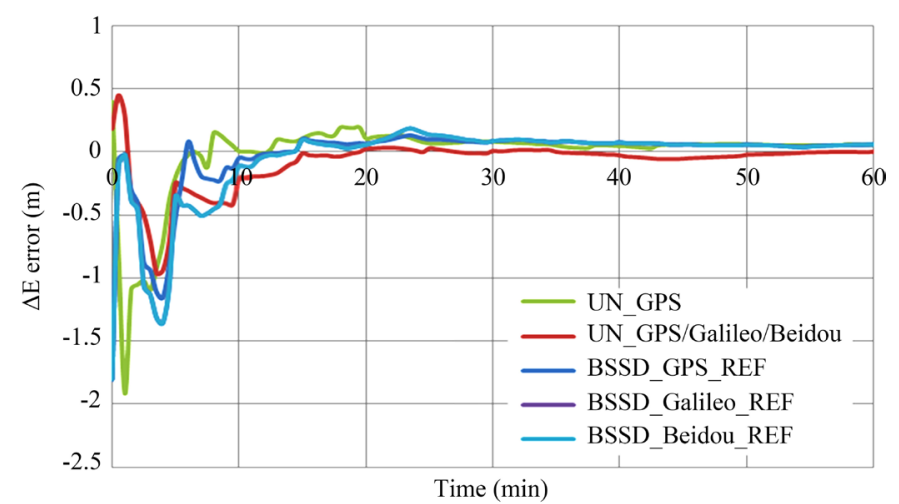

(a)

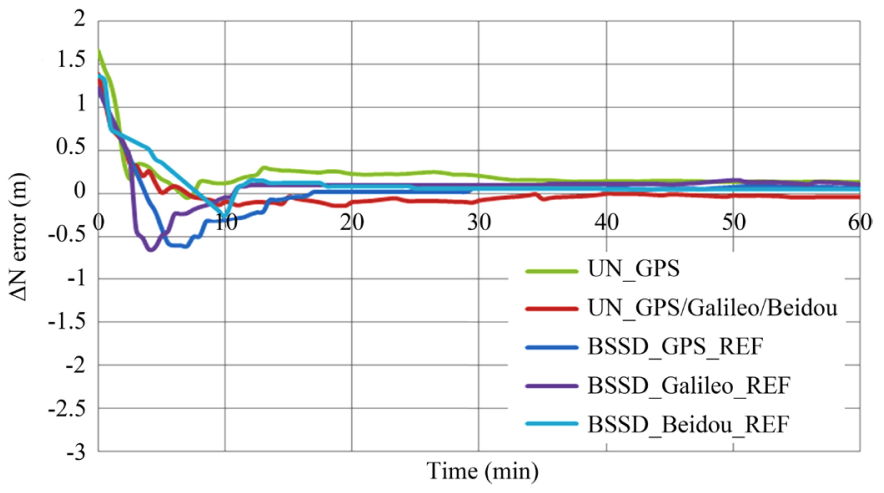

(b)

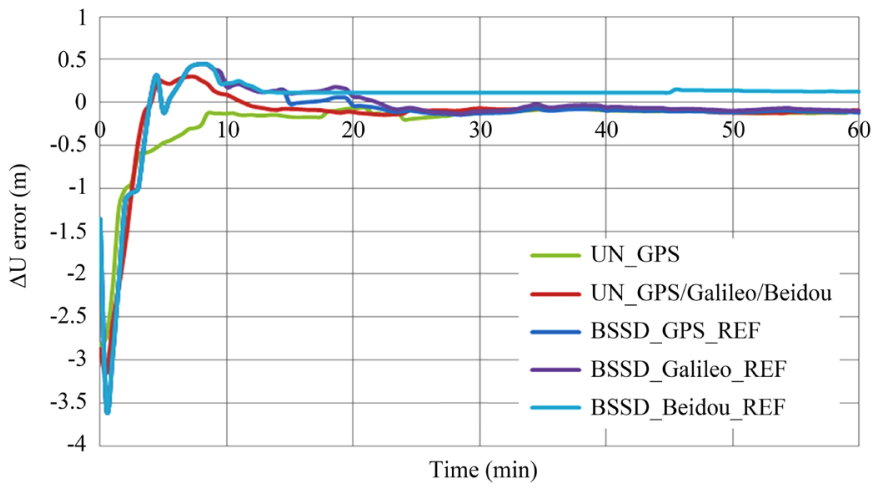

(c)

Figure 5. Positioning errors in East, North and Up directions.

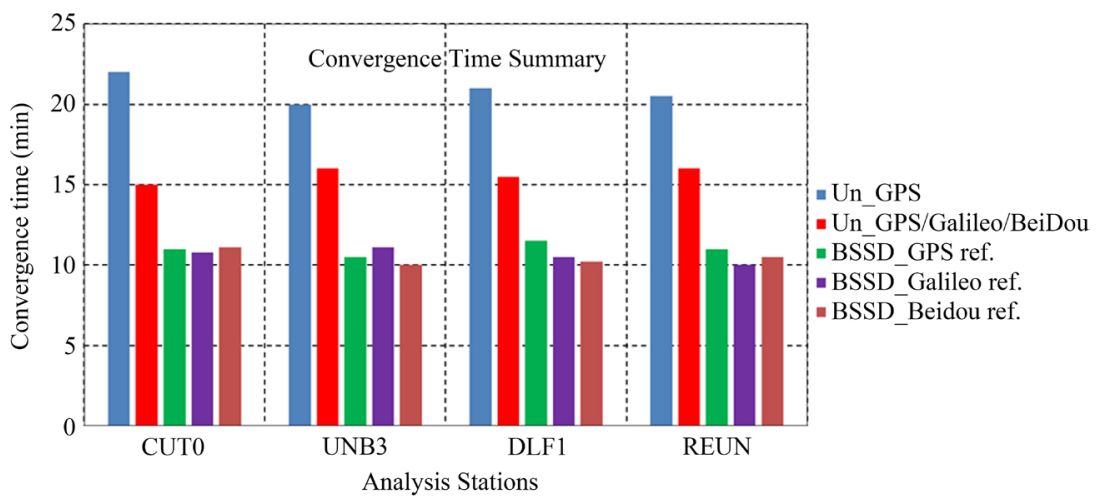

Figure 6. Summary of convergence times of all stations and PPP models. 


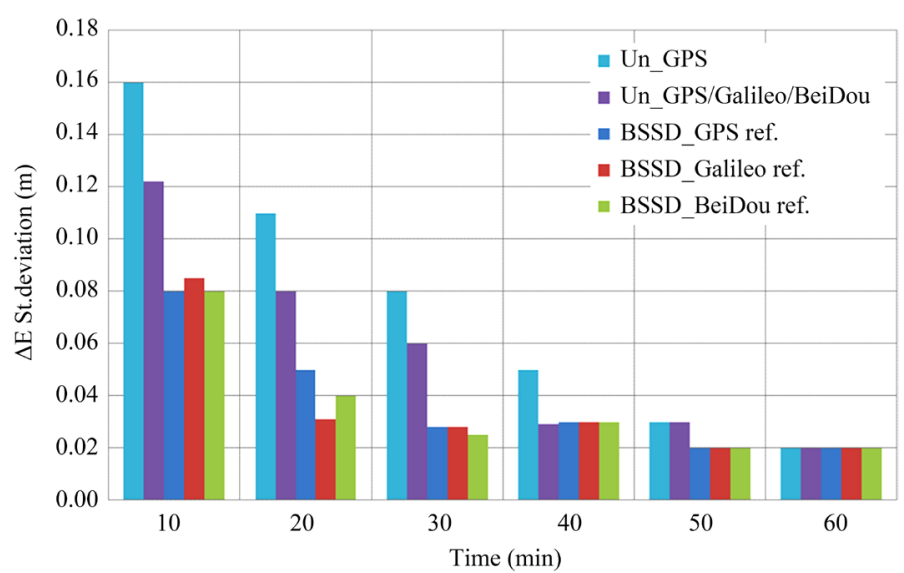

(a)

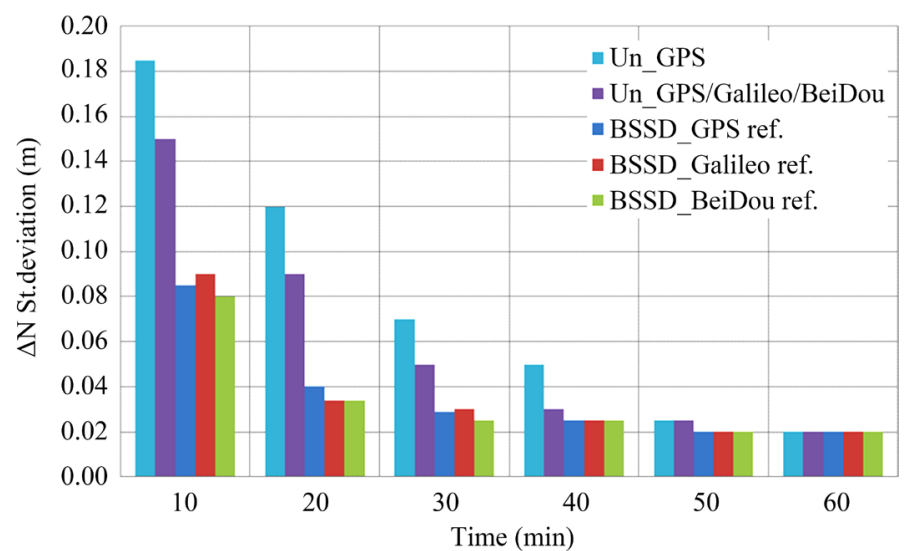

(b)

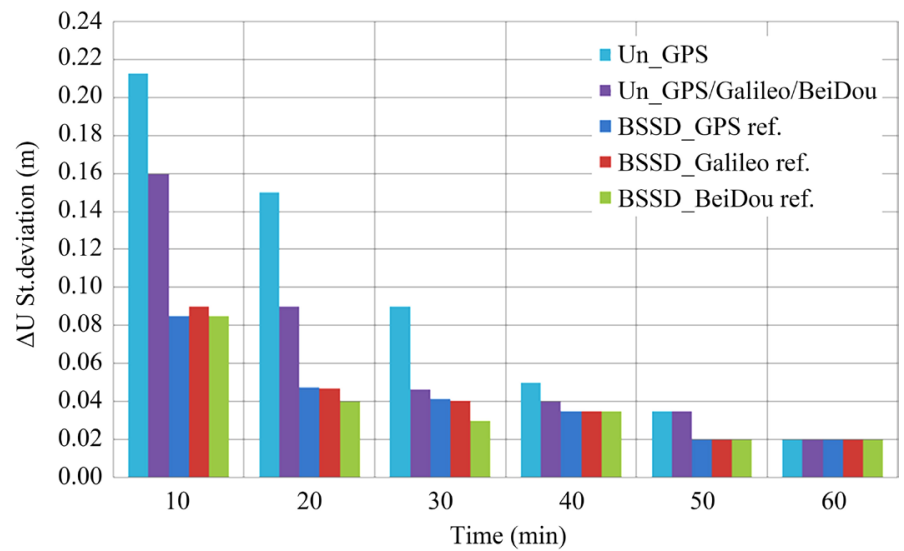

(c)

Figure 7. Summary of positioning standard deviations in East, North, and Up directions of all PPP models.

\section{Conclusion}

This paper presents a PPP model, which combines GPS, Galileo, and BeiDou observations in BSSD mode. Different reference satellite has been considered when forming BSSD, namely GPS reference satellite, Galileo reference satellite and BeiDou reference satellite. It has been shown that the newly developed PPP model improves the solution convergence time by about 50\%, in comparison with the un-differenced GPS-only PPP model. In addition, the newly developed model improves the precision of the estimated parameters by about $25 \%$, in com- 
parison with the un-differenced GPS-only model. As the number of epochs increases, the performance of the various models tends to be comparable. Almost identical results are obtained through the BSSD combination when either a GPS, Galileo or BeiDou satellite is selected as a reference.

\section{Acknowledgements}

This research was partially supported by the Natural Sciences and Engineering Research Council (NSERC) of Canada. The authors would like to thank the International GNSS service-Multi-GNSS Experiment (IGS-MEGX) network.

\section{References}

[1] Zumberge, J.F., Heflin, M.B., Jefferson, D.C., Watkins, M.M. and Webb, F.H. (1997) Precise Point Positioning for the Efficient and Robust Analysis of GPS Data from Large Networks. Journal of Geophysical Research, 102, 5005-5017. http://dx.doi.org/10.1029/96JB03860

[2] Kouba, J. and Heroux, P. (2001) Precise Point Positioning Using IGS Orbit and Clock Products. GPS Solutions, 5, 1228. http://dx.doi.org/10.1007/PL00012883

[3] Colombo, O.L., Sutter, A.W. and Evans, A.G. (2004) Evaluation of Precise, Kinematic GPS Point Positioning. ION GNSS 17th International Technical Meeting of the Satellite Division, 21-24 Septeber 2004, Long Beach, 1423-1430.

[4] Ge, M., Gendt, G., Rothacher, M., Shi, C. and Liu, J. (2008) Resolution of GPS Carrier-Phase Ambiguities in Precise Point Positioning (PPP) with Daily Observations. Journal of Geodesy, 82, 401. http://dx.doi.org/10.1007/s00190-007-0208-3

[5] Collins, P., Bisnath, S., Lahaye, F. and Héroux, P. (2010) Undifferenced GPS Ambiguity Resolution Using the Decoupled Clock Model and Ambiguity Datum Fixing. Navigation, 57, 123-135. http://dx.doi.org/10.1002/j.2161-4296.2010.tb01772.x

[6] Afifi, A. and El-Rabbany, A. (2014) Improved Model for Precise Point Positioning with Dual Frequency GPS/Galileo Observables. The International Archives of the Photogrammetry, Remote Sensing and Spatial Information Sciences. 2014 ISPRS Technical Commission II Symposium, Vol. XL-2, 6-8 October 2014, Toronto, 173-177.

[7] Hofmann-Wellenhof, B., Lichtenegger, H. and Wasle, E. (2008) GNSS Global Navigation Satellite Systems; GPS, Glonass, Galileo \& More. Springer, Wien, New York, 501.

[8] Leick, A. (2004) GPS Satellite Surveying. 3rd Edition, John Wiley and Sons, Hoboken.

[9] Montenbruck, O., Steigenberger, P., Khachikyan, R., Weber, G., Langley, R.B., Mervart, L. and Hugentobler, U. (2014) IGS-MGEX: Preparing the Ground for Multi-Constellation GNSS Science. Inside GNSS, 9, 42-49.

[10] Tegedor, J., Liu, X., de Jong, K., Goode, M., Øvstedal, O. and Vigen, E. (2014) Estimation of Galileo Uncalibrated Hardware Delays for Ambiguity-Fixed Precise Point Positioning. Proceedings of the 27th International Technical Meeting of the Satellite Division of the Institute of Navigation (ION GNSS+ 2014), Tampa, September 2014, 23462353.

[11] Hopfield, H.S. (1972) Tropospheric Refraction Effects on Satellite Range Measurements. APL Technical Digest, 11, 11-19.

[12] Kouba, J. (2009) A Guide to Using International GNSS Service (IGS) Products. http://igscb.jpl.nasa.gov/igscb/resource/pubs/UsingIGSProductsVer21.pdf

[13] Afifi, A. and El-Rabbany, A. (2015) An Innovative Dual Frequency PPP Model for Combined GPS/Galileo Observations. Journal of Applied Geodesy, 9, 27-34. http://dx.doi.org/10.1515/jag-2014-0009

[14] Boehm, J. and Schuh, H. (2004) Vienna Mapping Functions in VLBI Analyses. Geophysical Research Letters, 31, L01603 01601-01604. http://dx.doi.org/10.1029/2003GL018984

[15] Bos, M.S. and Scherneck, H.-G. (2011) Ocean Tide Loading Provider. http://holt.oso.chalmers.se/loading/

[16] IERS (2010) International Earth Rotation and Reference System Services Conventions (2010). IERS Technical Note 36. http://www.iers.org/IERS/EN/Publications/TechnicalNotes/tn36.html/

[17] Wu, J.T., Wu, S.C., Hajj, G.A., Bertiger, W.I. and Lichten, S.M. (1993) Effects of Antenna Orientation on GPS Carrier Phase. Manuscripta Geodaetica, 18, 91-98.

[18] Kaplan, E. and Heagarty, C. (2006) Understanding GPS Principles and Applications. Artech House Inc., 703.

[19] Dow, J.M., Neilan, R.E. and Rizos, C. (2009) The International GNSS Service in a Changing Landscape of Global Navigation Satellite Systems. Journal of Geodesy, 83, 191-198. http://dx.doi.org/10.1007/s00190-008-0300-3 
[20] Paziewski, J. and Wielgosz, P. (2014) Assessment of GPS + Galileo and Multi-Frequency Galileo Single-Epoch Precise Positioning with Network Corrections. GPS Solutions, 18, 571-579.

[21] Vanicek, P. and Krakiwsky, E.J. (1986) Geodesy: The Concepts. 2nd Edition, North-Holland, Amsterdam. 